\title{
Berkes, F., J. Colding, and C. Folke. 2003. Navigating social- ecological systems: Building resilience for complexity and change. Cambridge University Press, Cambridge, UK.
}

\author{
Brian M. Starzomski
}

The management of natural resources is a complex problem that requires bridging disciplines, political boundaries, and temporal and spatial scales. The book Navigating Social-Ecological Systems: Building Resilience for Complexity and Change uses complex systems theory and draws on expertise in ecology, ecological economics, and political and social science to understand how human communities respond and adapt to change in their natural resources and linked socialecological systems. The book offers a broad perspective and presents the work of world leaders in management research and practice from Minnesota to Atlantic Brazil, from Northern Canada to Northern Tanzania. Navigating Social-Ecological Systems continues the research presented in Linking Social-Ecological Systems: Management Practices and Social Mechanisms for Building Resilience, edited by the same group and published in 2000. As with the previous book, the concept of resilience is central. The authors argue that building resilience in social-ecological systems will enable better management of natural resources, as well as increase human capacity to deal with change.

The book is divided into four sections: (1) Perspectives on resilience, (2) Building resilience in local management systems, (3) Social-ecological learning and adaptation, and (4) Cross-scale institutional response to change. The first of these sections presents the necessary theory to understand how people respond to surprises in management, and explores the contribution of resilience theory to understanding social-ecological system linkages. The superb Chapter 4, 'Redundancy and diversity: do they influence optimal management' by Low et al., explores the relationship between resilience and redundancy in various systems, from explicitly political systems to ecological systems rich in species. This is a very useful synopsis of similarities across systems, and an excellent example of successful multidisciplinarity.
The second section looks at the role of local-scale resilience in management of multi-scale systems. An interesting analysis of the response of several groups of resource users (Polynesian and Bangladeshi farmers, and African pastoralists) to large-scale disturbance is presented in Chapter 7, 'Living with disturbance: building resilience in social-ecological systems' by Colding, Elmqvist and Olsson. Here the authors describe risk-spreading strategies of communities to deal with variability and disturbance in natural systems. An important point is that the people in the communities described in the chapter anticipate and rely on the disturbance to continue cropproduction, and have various ways to deal with surprises in the normal cycle of disturbances.

The third section uses an adaptive management framework to explore various ways of learning from, and responding to, change in managed systems. In Chapter 8, Exploring the role of local ecological knowledge in ecosystem management: three case studies' by Gadgil et al., examples are given that detail ways of using local knowledge as a contemporaneous (along with conventional scientific techniques) way of collecting data on the system to be managed. Also useful in this chapter is an excellent discussion of the role of local-knowledge in a science-dominated world, detailing concerns and contexts for both local knowledge and scientifically collected information. This discussion presents methods for deciding how the two ways of knowing can be used together. These ideas are echoed in the summary Chapter 14, as well. Chapters 9 and 10 in this section are also useful, describing how adaptive management is and can be done in large-scale systems in Minnesota and Northern Canada.

The final section examines the role of institutional response to change, with examples from the 
institutions set up to regulate a lagoon fishery in Brazil that has many stakeholders demanding access to the lagoon, an indigenous movement in Indonesia that seeks a social renewal to adapt to massive changes to a traditional culture, and groups in the United States' forest sector responding to policy changes of the last 35 years.

The examples given throughout the book are very engaging. Clear descriptions of workable management practices are presented, with descriptions of how, for example, to be a skilled facilitator during public input meetings. Theory, when outlined, is easy to understand, and accompanied by examples where it has been put into practice, such as in the Maine lobster fishery. As a result, the book is very accessible, and this may be its greatest strength.

Navigating Social-Ecological Systems: Building Resilience for Complexity and Change follows the seminal contributions of Linking Social and Ecological Systems: Management Practices and Social Mechanisms for Building Resilience in providing actual prescriptions for increasing the resilience of managed systems. This volume goes further and presents a number of insights into the way linked social and ecological systems can be understood, and their adaptive capacity for response to change enhanced. Examples range from how to integrate local ecological knowledge (such as the monitoring of caribou fat content during hunts) into scientific management, to how farmers actually use a form of biodiversity-ecosystem functioning theory to protect their gardens from disturbance.

For those readers looking to increase their understanding of these linked systems, whether from an applied or a basic research point of view, I heartily recommend the book. Calls for multi-disciplinarity are frequently heard - seldom are they as well heeded as in this book, and seldom are they presented in such an accessible manner. If you are interested in the links between social and ecological systems to further your understanding of ecosystems, or because of concerns from applied ecology/management of natural resources, ignore this book at your peril. It is highly recommended for graduate students in ecology who crave the human-in-ecosystem perspective, though at U.S. $\$ 85$ the hardback edition may be out of their budget range. A paperback version of this book will likely soon be available for approximately U.S. \$35.

\section{BOOK INFORMATION}

Berkes, F., J. Colding, and C. Folke. 2003. Navigating social-ecological systems: Building resilience for complexity and change. Cambridge University Press, Cambridge, UK. 393 pp., hardcover, US \$85. ISBN: 05218-1592-4

Responses to this article can be read online at: http://www.ecologyandsociety.org/vol9/iss1/artl/responses/in dex.html

\section{LITERATURE CITED}

Berkes, F. and C. Folke. 1998. Linking social and ecological systems: management practices and social mechanisms for building resilience. Cambridge University Press, Cambridge, UK. 